\title{
THE ROLE OF LIBRARY IN DEVELOPING LITERACY OF SD N 4 KUTOSARI STUDENT
}

\author{
Nurjihan Hasanah, Listiyani, Solikhatun Diniah, Ratna Hidayah \\ Universitas Sebelas Maret \\ jihankamila79@gmail.com
}

\section{Article History}

accepted 30/09/2018

approved 12/10/2018

published 30/10/2018

\section{Keywords}

Developing literacy, library

\begin{abstract}
This title of research: "The role of library in developing literacy of SD N 4 Kutosari Student". The focus of the study in this research is: (1) How the role of library in developing literacy of $S D N 4$ Kutosari Student ? (2) How the impact of library in in developing literacy of SD N 4 Kutosari Student? Based on the formulation of the problem, this research has purposes: (1) Identify role of libraries in developing literacy of SD N 4 Kutosari Student. (2) Identify the impact of library in developing literacy of SD N 4 Kutosari Student. Techniques of data collection in this research are through literacy reading on cases, proceed with the questionnaire distribution, and lastly by drawing the conclusion.
\end{abstract}

Social, Humanities, and Education Studies (SHEs): Conference Series https://jurnal.uns.ac.id/shes 


\section{PENDAHULUAN}

Perkembangan zaman dan kemajuan IPTEK yang semakin pesat menuntut setiap orang untuk mempunyai kemampuan berliterasi. Literasi merupakan salah satu keterampilan yang sangat dibutuhkan dalam hidup. Semua proses belajar didasarkan pada kemampuan membaca, yang merupakan bagian dari literasi. Membaca diperlukan untuk memperoleh pengetahuan dan wawasan yang luas untuk meningkatkan kecerdasan seseorang. Budaya membaca harus diterapkan sejak seseorang mengenyam pendidikan di sekolah dasar. Hal ini bertujuan agar seseorang dapat mengikuti perkembangan zaman yang semakin canggih. Perpustakaan sebagai sumber informasi di sekolah, mempunyai peran sangat penting dalam proses belajar mengajar. Perpustakaan juga sangat berperan dalam meningkatkan kemampuan literasi siswa.

Kemampuan literasi peserta didik di Indonesia berkaitan erat dengan ketrampilan membaca yang berkelanjutan pada kemampuan memahami analitis, kritis, dan reflektif. Perlu diketahui bahwa literasi merupakan kemampuan mengakses, memahami, dan menggunakan informasi secara cerdas. Kegiatan literasi selama ini identik dengan aktivitas membaca dan menulis, namun sesuai dengan Deklarasi Praha pada tahun 2003 menyebutkan bahwa literasi juga mencakup bagaimana orang lain berkomunikasi dengan masyarakat. Literasi bemakna praktek dan hubungan sosial yang berkaitan dengan pengetahuan, bahasa dan budaya (UNESCO,2003). Deklarasi UNESCO juga menyebutkan bahwa literasi informasi terkait pula dengan kemampuan untuk mengidentifikasi, menentukan, menemukan, mengevaluasi, menciptakan, menggunakan, dan mengomunikasikan informasi untuk mengatasi berbagai persoalan Dirjen Dikdasmen dalam (Yulisa Wandasari,2017).

Literasi adalah salah satu kemampuan dasar yang harus dikuasai individu untuk mampu survive pada era global. Tidak adanya batasan ruang dan waktu dalam interaksi global menuntut individu untuk mampu berinteraksi serta berkomunikasi dengan berbagai media dan keterampilan literasi. Literasi adalah keterampilan berbahasa dalam konteks komunikasi. Pada konteks pembelajaran, literasi memegang peranan penting untuk mencapai tujuan pembelajaran baik pada tingkat mikro maupun makro. Untuk itu, literasi merupakan salah satu komponen penting yang menunjukkan kemajuan sistem pendidikan suatu bangsa. Berdasarkan penjelasan tersebut, dapat diidentifikasi bahwa kemampuan literasi menjadi pusat utama untuk mengembangkan pengetahuan sekaligus keterampilan pada bidang yang lain. Kurangnya kecakapan literat pada siswa berimbas pada ketidakmampuan siswa dalam mengembangkan keterampilan pada bidang lain. (Dewi Trynasari, 2017:174)

Di sekolah dasar kemampuan membaca memiliki peranan yang penting untuk menunjang kegiatan pembelajaran. Salah satu tempat yang digunakan untuk kegiatan membaca oleh siswa sekolah dasar yaitu perpustakaan. Selain sebagai tempat untuk menunjang kegiatan pembelajaran, perpustakaan juga merupakan tempat mengembangkan dan meningkatkan minat membaca di sekolah dasar. Hal ini sesuai dengan pendapat dari Komarudin (2012:20) yang mengemukakan bahwa perpustakaan sekolah memiliki peran penting dalam memenuhi keperluan pendidikan terutama sebagai sarana mengembangkan kecerdasan intelektual setiap peserta didik. Oleh karnea itu, mengabaikan keberadaan perpustakaan berarti mengurangi kesempatan bagi peserta didik dalam mengembangkan potensi yang dimiliki mereka.

Perpustakaan sekolah adalah suatu tempat yang berada di lembaga pedidikan yang dimanfaatkan sebagai penunjang belajar dan mengajar agar terciptanya masyarakat yang bertanggungjawab (Yanita Safilla 2014;16). Namun siswa sekolah dasar masih belum dapat memanfaatkan perpustakaan sesuai dengan perannya dengan baik. Minat siswa untuk berkunjung ke perpustakaan masih rendah. Ketua Forum Pengembangan Budaya Literasi Indonesia, Satria Darma mengungkapkan bahwa budaya literasi masyarakat Indonesia sangat rendah (Ika Nur Harini, 2017 : 1). 
Ungkapan ini dapat dibuktikan melalui penelitian yang kami lakukan di SD Negeri 4 Kutosari tentang "Peran Perpustakaan Dalam Mengembangkan Literasi Siswa SD Negeri 4 Kutosari”.

Rumusan masalah dari kajian ini adalah: 1) Bagaimana peran perpustakaan dalam mengembangkan literasi siswa SD Negeri 4 Kutosari? (2) Bagaimanakah dampak perpustakaan dalam mengembangkan literasi siswa SD Negeri 4 Kutosari? Berdasarkan rumusan masalah di atas, maka penelitian ini memiliki beberapa tujuan: (1) Mengidentifikasi peran perpustakaan dalam mengembangkan literasi siswa SD Negeri 4 Kutosari (2) Mengidentifikasi peran perpustakaan berkaitan dengan pengembangan literasi siswa SD Negeri 4 Kutosari.

\section{METODE}

Metode penelitian ini menggunakan penelitian survey. Penulis ingin menggambarkan kondisi yang ada di lapanagan sebagaimana adanya. Penelitian dilakukan dengan menggunakan sampel dari sebuah populasi. Populasi di SD Negeri 4 Kutosari berjumlah 251 siswa. Sampel dari penelitian ini adalah siswa di SD Negeri 4 Kutosari perwakilan kelas 1-6 sejumlah 60 siswa. Dimana penelitian ini menggunakan sampel SD N 4 Kutosari dengan sumber data berupa data primer dan data sekunder serta teknik dan alat pengumpulan data berupa angket. Teknik analisis data yang digunakan pada penelitian ini yaitu teknik analisis data angket, yang dianalisis menggunakan rumus persentase menurut Purwanto (2013:102) berikut ini :

$$
\begin{aligned}
& \mathrm{NP}=\frac{R}{S M} \times 100 \\
& \text { Keterangan : } \\
& \mathrm{NP} \quad: \text { nilai persen yang dicari atau diharapkan } \\
& \mathrm{R} \quad: \text { skor mentah yang diperoleh siswa } \\
& \mathrm{SM} \quad \text { : skor maksimum ideal dari tes yang bersangkutan } \\
& 100 \quad \text { : bilangan tetap }
\end{aligned}
$$

HASIL DAN PEMBAHASAN

Penelitian dilaksanakan pada hari Jumat tanggal 05 Oktober 2018 pukul 08.00 sampai dengan selesai di kelas 1-6 SD Negeri 4 Kutosari perwakilan 10 siswa per kelas.. Pada waktu yang ditentukan, peneliti memberikan angket peran perpustakaan dalam mengembangkan literasi siswa SD Negeri 4 Kutosari. Peneliti memberikan angket kepada perwakilan siswa untuk diisi sesuai dengan pengalaman pribadinya, kemudian setelah selesai angket dikumpulkan. Jumlah item pertanyaan dalam angket adalah 20 item dengan skor 1-3 sehingga rentang skor yang mungkin diperoleh adalah 20 sampai 60 per siswa. Skor minimal ideal adalah 20 dan skor maksimalnya adalah 60 per siswa.

Adapun indikator yang digunakan untuk menentukan perolehan skor dari masingmasing aspek berdasarkan jawaban siswa di angket adalah sebagai berikut :

1. Saat jam istirahat saya berkunjung ke perpustakaan.

2. Saat di perpustakaan saya membaca buku.

3. Saya meminjam buku di perpustakaan.

4. Saya meminjam buku di perpustakaan untuk belajar di kelas.

5. Saya meminjam buku di perpustakaan untuk belajar di rumah.

6. Saya meminjam buku cerita di perpustakaan.

7. Guru saya mengajak belajar membaca di perpustakaan.

8. Guru saya mengajak belajar menulis di perpustakaan.

9. Guru saya mengajak belajar berhitung di perpustakaan.

10. Guru mengajak saya membaca buku dari perpustakaan di depan teman kelas. 
11. Perpustakaan membuat saya lebih rajin membaca.

12. Perpustakaan membuat nilai saya meningkat.

13. Perpustakaan menjadikan saya rajin belajar.

14. Perpustakaan menjadikan saya pandai.

15. Perpustakaan menjadi tempat nyaman untuk belajar.

16. Perpustakaan sebagai tempat menambah ilmu.

17. Perpustakaan membuat saya semangat belajar.

18. Perpustakaan menjadikan saya tahu banyak hal baru.

19. Perpustakaan membantu saya menyelesaikan tugas sekolah.

20. Perpustakaan tempat saya mengisi waktu luang.

Dari persentase yang diperoleh, diinterpretasikan dan diklasifikasikan dengan pedoman penilaian yang diadaptasi dari pendapat Purwanto (2013:103) berikut ini :

Tabel 1. Pedoman Pengklasifikasian Peran Perpustakaan dalam Mengembangkan Literasi Siswa SD Negeri 4 Kutosari

\begin{tabular}{cll}
\hline No & \multicolumn{1}{c}{ Presentase } & \multicolumn{1}{c}{ Kategori } \\
\hline 1 & $63 \%-100 \%$ & Sangat Baik \\
2 & $33 \%-62 \%$ & Baik \\
3 & $<32 \%$ & Kurang Baik \\
\hline
\end{tabular}

Berdasarkan data dari angket peran perpustakaan dalam mengembangkan literasi siswa SD Negeri 4 Kutosari yang telah dihitung, berikut ini adalah hasil grafiknya :

Grafik 1. Grafik Peran Perpustakaan dalam Mengembangkan Literasi Siswa SD Negeri 4 Kutosari

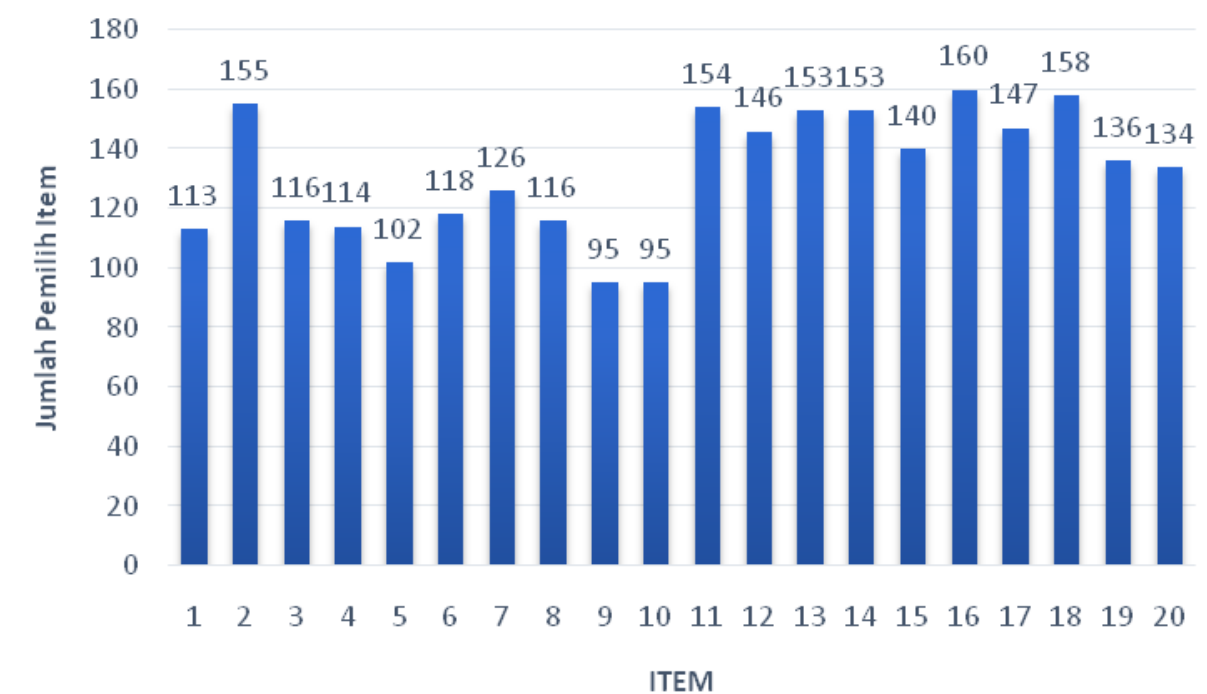

Berdasarkan grafik 1 kita ketahui bahwa skor tertinggi yang dipilih siswa SD Negeri 4 Kutosari terdapat pada item ke 16 dengan isi item yaitu perpustakaan sebagai tempat menambah ilmu, sedangkan skor terendah yang dipilih siswa SD Negeri 4 Kutosari terdapat pada item ke 9 dengan isi item yaitu guru saya mengajak belajar menulis di perpustakaan dan terdapat juga pada item ke 10 dengan isi guru mengajak saya membaca buku dari perpustakaan di depan teman kelas. Dari grafik tersebut dapat disimpulkan rata-rata skor mentah yang diperoleh siswa SD Negeri 4 Kutosari adalah 131,5 . 
Berdasarkan data dari angket peran perpustakaan dalam mengembangkan literasi siswa SD Negeri 4 Kutosari yang telah dihitung, berikut ini adalah hasil persentasenya :

Tabel 2. Hasil Persentase Peran Perpustakaan dalam Mengembangkan Literasi Siswa SD Negeri 4 Kutosari

\begin{tabular}{|c|c|c|c|c|c|}
\hline No & Pernyataan & $\begin{array}{l}\text { Skor } \\
\text { Mentah }\end{array}$ & $\begin{array}{c}\text { Skor } \\
\text { Maksimum }\end{array}$ & $\begin{array}{c}\text { Nilai } \\
\text { Presentase }\end{array}$ & Kategori \\
\hline 1 & $\begin{array}{l}\text { Saat jam istirahat saya } \\
\text { berkunjung ke perpustakaan. }\end{array}$ & 113 & 180 & $63 \%$ & Sangat Baik \\
\hline 2 & $\begin{array}{l}\text { Saat di perpustakaan saya } \\
\text { membaca buku. }\end{array}$ & 155 & 180 & $86 \%$ & Sangat Baik \\
\hline 3 & $\begin{array}{l}\text { Saya meminjam buku di } \\
\text { perpustakaan. }\end{array}$ & 116 & 180 & $64 \%$ & Sangat Baik \\
\hline 4 & $\begin{array}{l}\text { Saya meminjam buku di } \\
\text { perpustakaan untuk belajar } \\
\text { di kelas. }\end{array}$ & 114 & 180 & $63 \%$ & Sangat Baik \\
\hline 5 & $\begin{array}{l}\text { Saya meminjam buku di } \\
\text { perpustakaan untuk belajar } \\
\text { di rumah. }\end{array}$ & 102 & 180 & $57 \%$ & Baik \\
\hline 6 & $\begin{array}{l}\text { Saya meminjam buku cerita } \\
\text { di perpustakaan. }\end{array}$ & 118 & 180 & $66 \%$ & Sangat Baik \\
\hline 7 & $\begin{array}{l}\text { Guru saya mengajak belajar } \\
\text { membaca di perpustakaan. }\end{array}$ & 125 & 180 & $69 \%$ & Sangat Baik \\
\hline 8 & $\begin{array}{l}\text { Guru saya mengajak belajar } \\
\text { berhitung di perpustakaan. }\end{array}$ & 116 & 180 & $64 \%$ & Sangat Baik \\
\hline 9 & $\begin{array}{l}\text { Guru saya mengajak belajar } \\
\text { berhitung di perpustakaan. }\end{array}$ & 95 & 180 & $53 \%$ & Baik \\
\hline 10 & $\begin{array}{lcr}\text { Guru mengajak } & \text { saya } \\
\text { membaca } & \text { buku } & \text { dari } \\
\text { perpustakaan } & \text { di } & \text { depan } \\
\text { teman kelas. } & & \end{array}$ & 95 & 180 & $53 \%$ & Baik \\
\hline 11 & $\begin{array}{l}\text { Perpustakaan membuat } \\
\text { saya lebih rajin membaca. }\end{array}$ & 154 & 180 & $86 \%$ & Sangat Baik \\
\hline 12 & $\begin{array}{l}\text { Perpustakaan membuat nilai } \\
\text { saya meningkat. }\end{array}$ & 146 & 180 & $81 \%$ & Sangat Baik \\
\hline 13 & $\begin{array}{l}\text { Perpustakaan menjadikan } \\
\text { saya rajin belajar. }\end{array}$ & 153 & 180 & $85 \%$ & Sangat Baik \\
\hline 14 & $\begin{array}{l}\text { Perpustakaan menjadikan } \\
\text { saya pandai. }\end{array}$ & 153 & 180 & $85 \%$ & Sangat Baik \\
\hline 15 & $\begin{array}{lrr}\text { Perpustakaan } & \text { menjadi } \\
\text { tempat nyaman } & \text { untuk } \\
\text { belajar. } & & \end{array}$ & 140 & 180 & $78 \%$ & Sangat Baik \\
\hline 16 & $\begin{array}{l}\text { Perpustakaan sebagai } \\
\text { tempat menambah ilmu. }\end{array}$ & 160 & 180 & $89 \%$ & Sangat Baik \\
\hline 17 & $\begin{array}{l}\text { Perpustakaan membuat } \\
\text { saya semangat belajar. }\end{array}$ & 147 & 180 & $82 \%$ & Sangat Baik \\
\hline 18 & $\begin{array}{l}\text { Perpustakaan menjadikan } \\
\text { saya tahu banyak hal baru. }\end{array}$ & 158 & 180 & $88 \%$ & Sangat Baik \\
\hline 19 & Perpustakaan membantu & 136 & 180 & $76 \%$ & Sangat Baik \\
\hline
\end{tabular}
sekolah. 

mengisi waktu luang.

Berdasarkan data hasil penelitian yang disajikan dalam tabel 2, kita ketahui bahwa secara keseluruhan peran perpustakaan dalam mengembangkan literasi siswa SD Negeri 4 Kutosari sangat baik. Hal ini terlihat hasil kategori dari setiap item. Sebanyak 17 item masuk kategori sangat baik dan 3 item masuk kategori baik. Hal tersebut dipengaruhi beberapa faktor yaitu sudah terjadwalnya kunjungan ke perpustakaan untuk masing-masing kelas dan fasilitas perpustakaan yang memadai dengan banyaknya buku dan tempat yang nyaman.

\section{SIMPULAN}

Berdasarkan penelitian yang dilakukan di SD Negeri 4 Kutosari dapat disimpulkan bahwa peran perpustakaan pada siswa sangat baik. Dengan kategori tertinggi yaitu perpustakaan sebagai tempat menambah ilmu. Hal ini meningkatkan kemampuan literasi bagi siswa SD Negeri 4 Kutosari terutama dalam hal kemampuan membaca.

\section{DAFTAR PUSTAKA}

Harini, Ika N. 2017. Tingkat Literasi Membaca Peserta Didik Kelas IV Di SD Muhammadiyah Bantul Kota. Diunduh dari http://digilib.uinsuka.ac.id/28619/2/13480071BAB-IIV-atau-VDAFTAR-PUSTAKA.pdf.Diakses pada tanggal 08 Oktober 2018

Komarudin.2012.Peran Perpustakaan STAIN Kediri Dalam Layanan Pemustaka. Diunduh dari : http://jurnal.iainkediri.ac.id/index.php/universum/article/view/258 pada tanggal 09 Oktober 2018

Purwanto, Ngalim.2013.Prinsip-prinsip dan Teknik Evaluasi Pembelajaran. Bandung : PT Remaja Rosdakarya

Safilla, Yanita.2014.Peran Perpustakaan SD An-Nissa dalam Meningkatkan Literasi Informasi.Jakarta: UIN Syarif Hidayatulloh. Diunduh dari http://repository.uinjkt.ac.id/dspace/bitstream/123456789/29607/3/YANITA\%20S AFILLA-FAH.pdf Diakses pada tanggal 08 Oktober 2018

Trynasari, Dewi.2017.Pembelajaran Literasi di SDN Rejosari 1 Kecamatan Kawedanan Kabupaten Magetan. Premiere Educandum 7(2). Diakses dari https://www.researchgate.net/publication/322098015 Pembelajaran Literasi di SDN Rejosari 1 Kecamatan Kawedanan Kabupaten Magetan. Diakses pada tanggal 09 Oktober 2018

Wandasari, Yulisa.2017. Implementasi Gerakan Literasi Sekolah (GLS) Sebagai Pembentuk Pendidikan Berkarakter. Diunduh dari https://media.neliti.com/media/publications/230884-implementasi-gerakanliterasi-sekolah-gl-fecb51ed.pdf. Diakses pada tanggal 08 Oktober 2018 